\title{
A Comparative study of the techniques of Myringoplasty - Overlay Underlay \& Interlay
}

\author{
Dr.Rahul Kawatra ${ }^{1}$, Dr.Puneet Maheshwari ${ }^{1}$, Dr.Gaurav Kumar ${ }^{1}$ \\ ${ }^{1}$ (Deptt. Of ENT, Era' Lucknow Medical College \& Hospital, India)
}

\begin{abstract}
Background: Myringoplasty is a surgical technique used to restore the integrity of tympanic membrane and to improve hearing level.

Objective: To compare the three surgical modalities for Myringoplasty - Overlay, Underlay and Interlay in cases of Chronic Suppurative Otitis Media with Inactive Mucosal Disease in large central perforation.

Material and Methods: This is a prospective study of 18 months (January 2013 to June 2014) duration conducted in department of E.N.T, Era's Lucknow Medical College, Lucknow and data was collected from the 90 patients admitted for Myringoplasty. 30 in each group. Results were calculated in terms of graft accepted or rejected and decrease in air bone gap.
\end{abstract}

Result: Maximum number of graft rejection were observed in Overlay 5/30 and minimum in Interlay 2/30. Post operatively after 16 weeks mean air bone gap was maximum reduced in Interlay and minimum in Overlay Myringoplasty.

Conclusion: The present study showed that Interlay technique had a better graft take and hearing improvement in large central perforation of Chronic Suppurative Otitis Media.

Keywords: Chronic Suppurative Otitis Media, Interlay, Myringoplasty, Overlay, Underlay.

\section{Introduction}

Perforation of the tympanic membrane primarily results from middle ear infections, trauma or iatrogenic causes. Up to $80 \%$ of these perforations heal spontaneously [1]; For the remaining, Surgical repair, known as Myringoplasty, is usually proposed. Myringoplasty is a surgical technique used to restore the integrity of tympanic membrane and to improve hearing level [2]. It was introduced by Berthold [3]. Repair of eardrum by doing Myringoplasty may confer considerable benefits to patients with tympanic membrane perforation that include prevention of ear infections, aural discharge, improvement in hearing, to protect against long-term middle ear damage by preventing the ossicular pathology and preventing the migration of squamous epithelium around the margins of perforation with possible consequent Cholesteatoma formation [4].

Chronic Otitis Media is an inflammatory process in the middle-ear space that results in long-term or more often permanent changes in the tympanic membrane including Atelactasis, Dimeric, Perforation, Tympanosclerosis, Retraction pocket development, or Cholesteatoma. This results in long-term eustachian tube dysfunction with poorly aerated middle-ear space, multiple bouts of Acute Otitis Media or persistent middle ear infection. This is classified as Active, Inactive and Inactive with frequent reactivation [5]. Myringoplasty was introduced long back in 1878 by Berthold [3] and included the surgical closure of tympanic membrane perforation including removal of epithelium and grafting with skin. In 1950s, Zollner [6] and Wullstein [7] reintroduced Myringoplasty. This period witnessed an improvement in surgical techniques with improved optics and emergence of microsurgery, thus making the Myringoplasty safer and lowered the rate of graft rejection.

Many techniques of Myringoplasty are described in the literature. A few of the numerous techniques include Underlay [8], Overlay [9], Interlay. Although different types of grafts such as autogenous, homologous and allografts have been attempted for performing Myringoplasty but temporalis fascia graft remains the mainstay of almost all the procedures of Myringoplasty. Different advantages for the use of temporalis fascia graft include its physiological similarity with tympanic membrane [10].

Each technique has its advantage as well as disadvantage. Some of the workers are of the view that Overlay technique is more useful in repairing large and anterior perforation while Underlay technique is ideal for posterior perforation [11], Underlay technique is considered technically easier, less time-consuming and has shown to be having higher success rate [12]. Interlay technique is also considered to be better than Overlay as getting an Interlay plane (Between the fibrous layer and mucosa) is easier and faster than getting an Overlay plane (Between the epithelium and fibrous layer) and having no fear of residual epithelium. The Interlay approach has shown promising results with success rates higher than $90 \%[13,14,15,16]$.

The present study is an attempt to compare the three commonly used Myringoplasty procedures, Overlay, Underlay and Interlay in cases of Chronic Suppurative Otitis Media in large central perforation. 


\section{Aim of the Study}

To compare the three surgical modalities of Myringoplasty in cases of Chronic Suppurative Otitis Media with Inactive Mucosal Disease in large central perforation in terms of graft take up and improvement in hearing.

\subsection{Study Design and Setting}

\section{Material and Methods}

This Randomized prospective crossover study was carried in the Department of E.N.T, Era's Lucknow Medical College and Hospital, Lucknow in 90 patients of Chronic Suppurative Otitis Media (CSOM) with conductive hearing loss. This study was conducted after clearance from the Ethical Committee. Patients were properly informed regarding the nature of the disease process, proposed surgical procedure including expected outcomes, potential complications and alternative treatments. Written consent was signed by patient and attendant both.

\subsection{Study Period}

The duration of the study was 18 Months from January 2013 to June 2014 with 4 months follow-up period for every case.

\subsection{Sample Size}

90 patients from outpatient department of E.N.T, Era's Lucknow Medical College, Lucknow

\subsection{Procedure}

All cases of Chronic Otitis Media with large central perforation and conductive hearing loss (After diagnosing by Pure Tone Audiometry and Otomicroscopy) were admitted in the E.N.T. ward, relevant history, clinical findings, tuning fork tests, routine investigations along with X-Ray mastoid and Diagnostic Nasal Endoscopy (DNE) were carried out. Pre-operatively all patients had a Pure Tone Audiogram with an average of four frequency $(0.5 / 1 / 2 / 4 \mathrm{Khz})$ calculated for both air conduction and bone conduction. Post auricular approach and temporalis fascia was used as a graft material in all the three techniques of Myringoplasty under General Anesthesia.

Overlay technique were done in 30 patients having dry ear done by conventional method and temporalis fascia graft was placed lateral to the annulus and remaining fibrous middle layer after the squamous layer had been removed [17]. Fig.i

Underlay technique were done in 30 patients having dry ear done by conventional method and temporalis fascia graft was placed under the membrane remnant including the flap after elevating the tympanomeatal flap elevated along with annulus [18]. Fig.ii

Interlay technique were done in 30 patients having dry ear fibro-squamous layer, The remnant tympanic membrane along with the annulus was elevated leaving behind the mucosal layer. Temporalis fascia graft was placed between fibrous layer and the endothelial (Mucosal) layer the drum remnant. Fig.iii

Follow up of the patients done weekly in first operative month, Biweekly for next two month followed by final visit after four month. At every follow Up, patients were examined under ear microscopy to check the graft uptake and complication (If any). Post-operatively a Pure Tone Audiogram Using (0.5/1/2/4 Khz) was performed at 16 week (Last) follow-up. Hearing results were assessed by comparing pre-operative and postoperative pure tone averages as well as closure of the air-bone gap.

\subsubsection{Inclusion Criteria}

Cases of Chronic Otitis Media Inactive mucosal disease with pure conductive hearing loss.

Both males and females in the age group of 15-50 years were included in the study.

\subsubsection{Exclusion Criteria}

Patient with Sensorineural hearing loss and Mixed hearing loss.

Chronic Suppurative Otitis Media Squamosal disease with or without complications.

Patients below 15 years and above 50 years were excluded from the study.

Discharging ear, Previous history of ear surgery, Ossicular chain necrosis, Otitis externa.

Comorbid systemic diseases like Hypertension, Diabetes or any chronic infections.

Active focus found in nose, throat, oral cavity and history of allergy. 


\section{Statistical Tools Employed}

The following statistical formulas were used

\subsection{Mean}

To obtain the mean, the individual observations were first added together and then divided by the number of observation.

\subsection{Standard Deviation: It is denoted by the greek letter $\sigma$ :}

$$
\sigma=\sqrt{\frac{\sum(X-\bar{X})^{2}}{n}}
$$

4.3. Chi Square Test:

$$
\chi^{2}=\sum \frac{(O-E)^{2}}{E}
$$

Where $\mathrm{O}=$ Observed frequency, $\mathrm{E}=$ Expected frequency

\subsection{Analysis Of Variance: Analysis Of Variance (ANOVA)}

\subsection{Paired "T" Test}

\section{Results}

Out of 90 cases enrolled in the study, a total of 30 (33.3\%) each were managed using Overlay, Underlay and Interlay methods and comprised groups I, II and III of the study respectively. Age of patients ranged from 15 to 47 years. Majority of patients in both the groups were aged between 21 and 40 years. Mean age of patients in groups I, II and III was $29.43 \pm 7.00,28.67 \pm 9.72$ and $29.70 \pm 8.80$ years respectively. In groups I and III, a total of $16(53.3 \%)$ patients each were males and remaining 14 (46.7\%) were females however, in group II, exactly half $(\mathrm{n}=15 ; 50 \%)$ patients were males and remaining $15(50 \%)$ were females. Majority of patients in groups I and III, and exactly half the patients in group II were from urban areas. In group I, a total of $11(36.7 \%)$ and in groupIII, a total of $12(40 \%)$ patients were from rural areas.

\subsection{Mean hearing gain (Closure in air-bone gap)}

Air bone gap ranged from 15 to $35 \mathrm{db}$ in different groups. Half or more than half the cases in all the three groups had air-bone gap in the range of 20 to $25 \mathrm{db}$. There were $30 \%$ cases in group I, $23.3 \%$ in group II and $50 \%$ in group III had air bone gap of 30 or more. Preoperative mean air bone gap in groups I, II and III was $24.50 \pm 6.07,25.33 \pm 4.90$ and $27.50 \pm 5.53 \mathrm{db}$ and postoperative mean air bone gap was $16.50 \pm 6.04,14.67 \pm 4.54$ and $13.67 \pm 5.56$ respectively shown in (Table I).

\begin{tabular}{|c|c|c|c|c|c|c|c|c|}
\hline Groups & \multicolumn{2}{|c|}{ Preoperative } & \multicolumn{2}{|c|}{$\begin{array}{c}\text { Post-Operative Last } \\
\text { Follow Up }\end{array}$} & \multicolumn{2}{|c|}{ Change } & \multicolumn{2}{|c|}{$\begin{array}{c}\text { Significance Of Change } \\
\text { (Paired 'T'-Test) }\end{array}$} \\
\hline \multirow[b]{2}{*}{ Group I } & Mean & SD & Mean & SD & Mean & SD & "T" & "P" \\
\hline & 24.50 & 6.07 & 16.50 & 6.04 & -8.00 & 3.85 & 11.379 & $<0.001$ \\
\hline Group II & 25.33 & 4.90 & 14.67 & 4.54 & -10.83 & 7.63 & 7.661 & $<0.001$ \\
\hline Group III & 27.50 & 5.53 & 13.67 & 5.56 & -13.83 & 8.88 & 8.537 & $<0.001$ \\
\hline \multirow{2}{*}{\multicolumn{3}{|c|}{ Intergroup Comparison Of Reduction (ANOVA) }} & \multirow{2}{*}{\multicolumn{2}{|c|}{$\mathrm{F}$}} & \multicolumn{2}{|c|}{5.058} & & \\
\hline & & & & & \multicolumn{2}{|c|}{0.008} & & \\
\hline
\end{tabular}

Table I : Change in air bone gap in all three groups at last follow up (16 Weeks)

In all the three groups a significant mean reduction in air bone gap was observed. Mean reduction was maximum in group III and minimum in group I. Statistically, intergroup difference in reduction in air bone gap was significant $(\mathrm{p}<0.001)$

\subsection{Graft status (Accepted or Rejected)}

Out Of 90 Cases, Graft failure was observed in only 11 cases $(12.22 \%$ ), a success rate of $87.78 \%$ was observed in the present study. Success rate was $83.3 \%, 86.7 \%$ and $93.3 \%$ in group I, II and III respectively. Least graft failure rate was found in group III (Interlay Myringoplasty) shown in (Table II).

Table II: Outcome graft Accepted or Rejected (At 16 Weeks)

\begin{tabular}{|c|c|c|c|c|c|c|}
\hline \multirow{2}{*}{ Parameter/ Variable } & \multicolumn{2}{|c|}{ Group I (Overlay) (N=30) } & \multicolumn{2}{c|}{ Group II (Underlay) (N=30) } & \multicolumn{2}{c|}{ Group III (Interlay) (N=30) } \\
\cline { 2 - 7 } & No. & $\%$ & No. & $\%$ & No. & $\%$ \\
\hline Rejected/Failed & 5 & 16.7 & 4 & 13.3 & 2 & 6.7 \\
\hline Accepted/Successful & 25 & 83.3 & 26 & 86.7 & 28 & 93.3 \\
\hline
\end{tabular}




\section{Discussion}

Chronic suppurative otitis media is the result of an initial episode of acute otitis media and is characterized by a persistent discharge from the middle ear through a tympanic membrane perforation. It is an important cause of preventable hearing loss, particularly in the developing world. According to a WHO report, India is amongst the nations with highest burden of CSOM [19].

Myringoplasty is the simplest operative procedure performed to repair the perforation in ear drum by repairing the tympanic membrane only. It is performed when only except for ear drum, the entire ossicular chain is intact [7]. Myringoplasty is a beneficial procedure to protect the middle ear and inner ear from future deterioration. The improvement of hearing is obtained [20]. Although Myringoplasty involves simple closure of tympanic membrane, however, there are at least a dozen approaches to perform this procedure among these the Underlay and Overlay is quite common and are widely used. For the last few years, a new technique Interlay has also emerged and is being successfully used with promising results. The reported differences in immediate success rates are very nominal and hence each of these techniques is claimed to be having an equal if not better efficacy than the other [21].

In Overlay technique graft rejected in 5 patients. Preoperative mean air bone gap was $24.50 \mathrm{db}$ which comes to be $16.50 \mathrm{db}$. Postoperative there was change in $8.00 \mathrm{db}$ mean hearing gain after 16 weeks.

In Underlay technique graft rejected in 4 patients. Preoperative mean air bone gap was $25.33 \mathrm{db}$ which comes to be $14.67 \mathrm{db}$. Postoperative there was change in $10.83 \mathrm{db}$ mean hearing gain after 16 weeks.

In Interlay technique graft rejected in 2 patients. Preoperative mean air bone gap was $27.50 \mathrm{db}$ which comes to be $13.67 \mathrm{db}$. Postoperative there was change in $13.83 \mathrm{db}$ mean hearing gain after 16 weeks.

No complication noticed in any of the three procedures. Eventually the success rate was $83.3 \%$ in Overlay, $86.7 \%$ in Underlay and $93.3 \%$ in Interlay. The results for Interlay technique were in close proximity with the results obtained by komune [13] who observed a success rate of $94.2 \%$ for Interlay technique. While guo [14] reported $96.2 \%$, she [22] reported $87.5 \%$, hay and blanshard [16] reported $91 \%$ showing high success rate in Interlay Myringoplasty.

As far as air bone gap resolution is concerned, the results shown are variable in different studies for different techniques. crovetto [23] in their series showed post-operative air bone gap in the range 0 to $<20 \mathrm{db}$ in $88.4 \%$ of Underlay and $83.0 \%$ of Overlay patients, She [22] reported the mean reduction in air bone gap to be $4.9 \mathrm{db}$ in the Underlay and $9.7 \mathrm{db}$ in Over-Under group however, Patil [24] in their series of 100 cases who were approached using Interlay method showed a phenomenal reduction in air bone gap from a pre-operative mean value of $36.42 \pm 12.0 \mathrm{db}$ to $9.7 \pm 6.71 \mathrm{db}$, thus showing a reduction of almost $26.72 \mathrm{db}$.

In accordance with the observations in these studies, we found post-operative air bone gap to be within $15 \mathrm{db}$ range in $63.3 \%$ of Overlay and $86.7 \%$ each for Underlay and Interlay methods. In Interlay method we achieved air bone gap up to $10 \mathrm{db}$ in majority $(56.7 \%)$ of cases.

Thus in present study as far as resolution of air bone gap is concerned, Interlay technique showed a statistically significant better outcome as compared to the other two groups (Overlay and Underlay). The findings in present study showed a better graft take in Interlay method which coupled with a better postoperative air bone gap provided a better overall outcome.

\section{Conclusion}

Myringoplasty is a safe and effective technique to improve the quality of life of patients, avoiding continuous infections and allowing them contact with environment. Myringoplasty is a beneficial procedure to protect the middle ear and inner ear from future deterioration. The present study showed that Interlay technique had a better graft take and hearing improvement. The trends obtained indicated it to be a better approach than the other two methods ie. Underlay and Overlay Myringoplasty, in large safe central perforations.

\section{References}

[1]. Galdstone HB, Jackler RK, Varav K. Tympanic Membrane Wound Healing. An Overview. Otolaryngol Clin North Am., 28, 1995, 913-932.

[2]. Aslam MA, Aslam MJ. Comparison Of Over-Underlay And Underlay Techniques Of Myringoplasty. Pak. Armed Forces Med. J,3, 2009.:

[3]. Berthold E, Ueber Myringoplastik, Wier Med Bull, 1878, 1, 627-627, Cited By: Sismanis A. Tympanoplasty, In GlasscockShambaugh Surgery Of The Ear, Vol. 1, 5th Edn, Pp. 463-486, BC Decker Inc., 2003.

[4]. Bluestone CD, Cantekin EI, Douglas GS, Eustachian Tube Function Related To The Results Of Tympanoplasty In Children. Laryngoscope, 89, 1979 89, 450-8.

[5]. Nadol JB, The Chronic Draining Ear. In: Gates GA (Ed.). Current Therapy In Otolaryngology - Head And Neck Surgery, BC Decker Inc., Philadelphia, 1987, 18-22.

[6]. Zollner F, The Principles Of Plastic Surgery Of The Sound-Conducting Apparatus, J Laryngol Otol, 69,1955, 637-652.

[7]. Wullstein H, Theory And Practice Of Myringoplasty. Laryngoscope,66, 1956, 1076-93.

[8]. Shea JJ Jr, Vein Graft Closure Of Eardrum Perforation, J Laryngol Otol. 1960; 74: 358-62.

[9]. House WF, Myringoplasty, Arch Otolaryngol, 71, 1960, 399-404.

[10]. Sheehy JL, Crabtree JA, Tympanoplasty, Staging The Operation, Laryngoscope, 83, 1973, 1594-1621. 
[11]. Kartush JM, Michaelides EM, Becvarovski Z, Larouere MJ, Over-Under Tympanoplasty, Laryngoscope, 112, 2002, 802-7.

[12]. Singh M, Rai A, Bandyopadhyay S, Gupta SC, Comparative Study Of Underlay And Overlay Techniques Of Myringoplasty In Large And Subtotal Perforations Of The Tympanic Membrane, J Laryngol Otol, 117(6), 2003, 444-8.

[13]. Komune S, Wakizono S, Hisashi K, Uemura T, Interlay Method For Myringoplasty. Larynx Auris Nasus, 19(1), 1992,17-22.

[14]. Guo M, Huang Y, Wang J, Report Of Myringoplasty With Interlay Method In 53 Ears Perforation Of Tympani., Lin Chuang Er Bi Yan Hou Ke Za Zhi,13(4), 1999 Apr, 147-9.

[15]. Vishal US. A One-Year Prospective Study To Evaluate The Results Of Superiorly Based Tympanomeatal Flap In Endoscopic Myringoplasty Conducted In District Hospital, Belgaum And KLES And MRC, Belgaum During July 2003 To July 2004, Dissertation, MS (ENT), 2006, RGUHS, Karnataka.

[16]. Hay A, Blanshard J, The Anterior Interlay Myringoplasty:, Outcome And Hearing Results In Anterior And Subtotal Tympanic Membrane Perforations, Otol Neurotol.35(9), 2014 Oct,1569-76.

[17]. Sergi B, Galli J, De Corso E, Parrilla C, Paludetti G, Acta Otorhinolaryngol Ital, 31(6), Dec 2011, 366-371.

[18]. Sengupta A, Basak B, Ghosh D, Basu D, Adhikari D, Maity K, A Study On Outcome Of Underlay, Overlay And Combined Techniques Of Myringoplasty. Indian J Otolaryngol Head Neck Surg. 64(1), 2012, 63-6.

[19]. World Health Organization. Chronic Suppurative Otitis Media, Burden Of Illness And Management Options, WHO Child And Adolescent Health Department, Prevention Of Blindness And Deafness, Geneva, 2004.

[20]. Hussain A, Yousaf N, Khan AR, Outcome Of Myringoplasty. J Postgrad Med Inst.18, 2004, 693-6.

[21]. Kartush JM. Ossicular Chain Reconstruction. Capitulum To Malleus. Otolaryngol Clin North Am,27, 1994, 89-715.

[22]. She W, Dai Y, Chen F, Qin D, Ding X, Comparative Evaluation Of Over-Under Myringoplasty And Underlay Myringoplasty For Repairing Tympanic Membrane Perforation. Lin Chung Er Bi Yan Hou Tou Jing Wai Ke Za Zhi , 22(10), 2008, 433-5.

[23]. Crovetto De La Torre M, Fiz Melsió L, Escobar Martínez A, Myringoplasty In Chronic Simple Otitis Media, Comparative Analysis Of Underlay And Overlay Techniques, Acta Otorrinolaringol Esp.51(2), 2000 Mar, 101-4.

[24]. Patil BC, Misale PR, Mane RS, Mohite AA, Outcome Of Interlay Grafting In Type 1 Tympanoplasty For Large Central Perforation, Indian J. Otolaryngol. Head Neck Surg, 66(4), 2014, 418-424.

\section{Figures}

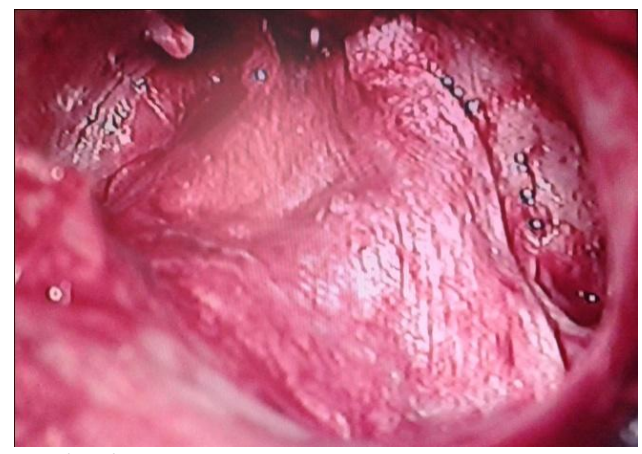

Fig. i Graft placed by Overlay technique

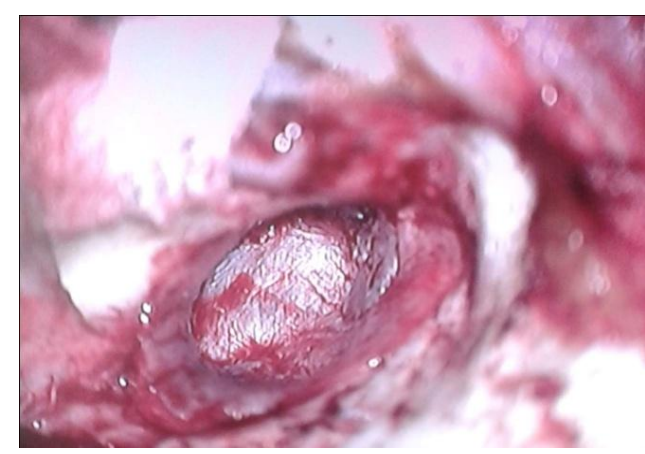

Fig. ii Graft placed by Underlay technique

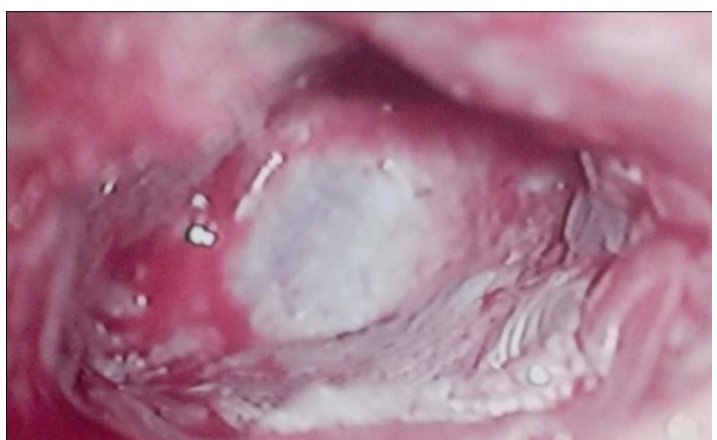

Fig. iii Graft placed by Interlay technique 